\title{
Controle dos Danos Ambientais Decorrentes da Deposição de Resíduos Sólidos na Sanga da Divisa, Quaraí-RS
}

\author{
Control of Environmental Damages Due to Deposition of \\ Solid Waste In "Sanga Da Divisa”, Quaraí-RS \\ ${ }^{1}$ Galidulcidio Rodrigues, ${ }^{2}$ Cibele Rosa Gracioli \\ ${ }^{1}$ Licenciado em Ciências Biológicas pela Universidade da Região da Campanha de Alegrete, \\ Especialista em Educação Ambiental, UFSM,RS, Brasil - e-mail: galidulcidio@hotmail.com (autor) \\ ${ }^{2}$ Engenheira Florestal e Doutora em Engenharia Florestal UFSM, RS, Brasil - \\ e-mail: cibelegracioli@gmail.com (orientadora)
}

\section{Resumo}

Nos dias atuais, o ambiente vem sendo constantemente degradado devido a ações antrópicas causadas pelo homem, à degradação de recursos naturais, como do solo e da água, cresce de forma alarmante, acarretando sérios prejuízos para todos os seres vivos. Considera-se a importância desses recursos para a manutenção e o equilíbrio da vida no planeta Terra, sendo que a água é recurso fundamental para a existência da vida. Levando em conta a crescente escassez da água em grande parte do mundo, pela poluição e contaminação do solo, justifica-se este estudo. Assim, o presente trabalho teve por objetivo geral retratar a degradação ambiental devido à deposição de resíduos sólidos em alguns pontos do córrego Sanga da Divisa, Quaraí - RS. Para isso, realizou-se uma coleta de dados e informações junto à Secretaria Municipal de Meio Ambiente do município e à EMATER, na busca de projetos voltados para a recuperação e preservação da área degradada. Através de registros fotográficos foi possível evidenciar a atual situação em que se encontra o córrego. Por fim, com base nos resultados obtidos neste trabalho, se propôs medidas de recuperação e preservação dessa área através de ações de Educação Ambiental para o controle dos danos ambientais, decorrentes da deposição de resíduos sólidos, e para conscientização da população local. Tendo em vista que estes resíduos dispostos inadequadamente têm alto potencial poluidor, além de favorecer a proliferação de vetores transmissores de doenças infecciosas e de microrganismos patogênicos, podem causar danos ao solo e à água.

Palavras-Chave: Danos Ambientais. Resíduos Sólidos. Sanga da Divisa

\begin{abstract}
:
Today the environment is constantly being degraded due to human actions caused by man, the degradation of natural resources as the soil and the water, grows alarmingly resulting in serious damage for all living beings. The importance of these resources is considered for the maintenance and the balance of life on Earth, given that water is the fundamental resource for the existence of life, taking into account its growing shortage largely in the world by the soil pollution and contamination, this study is justified. So the present study had as general purpose to picture the environmental degradation due to deposition of solid waste in some points of the stream Sanga da Divisa, Quaraí-RS, for it, a collection of data and information was held by the City Office of Environment and EMATER, in search of projects aimed to the recovery and preservation of the degraded area and through photographic record it was possible to evidence the current situation in which the stream is. Lastly, based on the results obtained in this study, it was proposed recovery and preservation measures of this area through actions of Environmental Education for the control of the environmental damages due to deposition of solid waste and awareness of local population. Given that this improperly disposed waste has high pollution potential, as well as favoring the proliferation of vectors transmitting infectious diseases and pathogenic microorganisms, it can cause damage to soil and water.
\end{abstract}




\section{Introdução}

A contaminação do ambiente por resíduos sólidos urbanos torna-se uma ação humana preocupante, uma vez que depositados em locais inadequados trazem graves consequências ambientais como a proliferação de vetores transmissores de doenças infecciosas e de microrganismos patogênicos, além de degradar o solo.

Observa-se um aumento na geração de resíduos no Brasil, isso devido ao acelerado crescimento populacional urbano e aos novos padrões de vida essencialmente consumista imposto pela sociedade industrial. No passado, os resíduos produzidos pela população eram, em sua maioria, compostos orgânicos facilmente degradados, no entanto, com a industrialização, onde cada vez mais são produzidos bens não duráveis, as características e o volume desses resíduos mudaram o que trás consequências graves para saúde pública e ambiental.

A deposição de resíduos sólidos em cursos d'água, próximos a áreas urbanizadas, tem aumentado constantemente nos últimos anos, ocasionando uma degradação ambiental. Os moradores que residem em áreas próximas a rios, lagos e sangas praticam esta ação diariamente, em sua maioria a população possui baixo nível de consciência no que toca à preservação ambiental e, normalmente, a coleta de resíduos efetuada se apresenta deficiente.

A degradação ambiental pode ser definida como qualquer processo que diminua a capacidade de determinado ecossistema em sustentar a vida. Esse processo está ligado a alterações biofísicas que afetam o desequilíbrio ambiental, modificando a fauna e flora natural, eventualmente causando perdas da biodiversidade. Tais alterações são muitas vezes associadas à ação antrópica, nos casos de desmatamento e poluição ambiental, embora também possam ocorrer por fatores naturais (WIKPÉDIA, 2014).

Considera-se a importância desses recursos para a manutenção e o equilíbrio da vida no planeta Terra, sendo que a água é recurso fundamental para a existência da vida, e levando em conta a sua crescente escassez em grande parte do mundo pela poluição e contaminação do solo. 
É diante dessa temática que o presente estudo teve por objetivo principal retratar a degradação ambiental que vem ocorrendo ao córrego Sanga da Divisa no município de QuaraíRS, em virtude da deposição de resíduos sólidos às suas margens.

Para alcançar este objetivo, foram traçados objetivos específicos como verificar a existência de projetos voltados à recuperação e preservação da área e quais os resultados obtidos, identificar os pontos da Sanga em que há deposição inadequada de resíduos sólidos e os possíveis impactos ambientais ali encontrados e posteriormente propor medidas de recuperação e preservação através de ações de Educação Ambiental para o controle dos danos ambientais e conscientização da população local.

\section{Metodologia}

A área que serviu como objeto de estudo do presente trabalho, situa-se no município de Quaraí na fronteira oeste do estado do Rio Grande do Sul. Um município brasileiro localizado a uma latitude $30^{\circ} 23^{\prime} 15^{\prime \prime}$ sul e a uma longitude $56^{\circ} 27^{\prime} 05^{\prime \prime}$ oeste, estando a uma altitude de 112 metros, distando de 595 quilômetros da capital estadual, Porto Alegre, e 2320 quilômetros da capital nacional, Brasília. Com uma população estimada em 23.021 habitantes e uma área de $3.148 \mathrm{~km}^{2}$ de extensão, conforme (IBGE, 2010), Quaraí faz parte do bioma pampa e é um dos maiores municípios gaúchos em área territorial, destacando-se na pecuária (bovinos e ovinos), na produção de arroz e no comércio, sendo este destaque.

A área em que se refere este estudo é o córrego Sanga da Divisa, que contorna a porção leste do município de Quaraí, possui cerca de cinco quilômetros de extensão e, é alimentada pelos subafluentes, Sanga da Areia e Sanga do Salso. Atualmente a Sanga da Divisa é considerada como o principal subafluente do rio Quaraí que é um dos principais afluentes do rio Uruguai.

A nascente da Sanga da Divisa situa-se a cerca de 900 metros da ponte da estrada do meio, para norte e nordeste e sua desembocadura se dá nas imediações da Ponte Internacional da Concórdia diretamente no rio Quaraí, ponte esta que se localiza sobre o rio Quaraí, e liga as cidades de Quaraí a Artigas no Uruguai.

Para este estudo serviu como base somente o trecho entre a ponte da BR 377 e a ponte da Avenida 20 de Setembro, uma vez que nesse local se iniciam os impactos ambientais com maior proporção tendo em vista a ocupação urbana.

O presente trabalho foi realizado entre os meses de agosto e dezembro do ano de 2014, a fim de retratar a degradação ambiental devido à deposição de resíduos sólidos em alguns pontos do córrego Sanga da Divisa, Quaraí-RS e apontar algumas medidas mitigadoras para o controle dos danos ambientais decorrentes dessa deposição na área, para isso foram adotados os seguintes procedimentos metodológicos:

Coleta e informações de dados: As informações e os dados coletados referentes à área foram obtidos junto a Secretaria Municipal de Meio Ambiente e EMATER (Empresa de Assistência Técnica e Extensão Rural) do município, na busca da existência de projetos voltados à recuperação e preservação da Sanga da Divisa e ainda verificar se há ou se já houve projetos de Educação Ambiental no município de Quaraí relacionados ao córrego Sanga da Divisa e quais os resultados obtidos.

Registros fotográficos da área: A partir de visitas em campo no mês de setembro, portando uma câmera digital PC14 PRS Philco realizou-se registros fotográficos no trecho localizado entre a Ponte da BR 377 e a ponte da Avenida 20 de Setembro, sendo possível identificar os pontos em que há deposição inadequada de resíduos sólidos às margens da Sanga. Além disso, foram evidenciados outros danos ambientais como a deposição de restos de matérias de construção, lançamento de esgoto cloacal diretamente no córrego e a ausência da mata ciliar em diversos pontos.

Medidas de recuperação e preservação da área: Com base nos resultados obtidos neste trabalho, foi possível propor algumas medidas de recuperação e preservação da área do córrego 
em que se encontra degradada devido à deposição inadequada de resíduos sólidos, além de promover a conscientização da população local, através de ações de Educação Ambiental.

\section{Resultados e Discussão}

\section{Projetos voltados para recuperação e preservação da área}

$\mathrm{Na}$ busca de projetos voltados a recuperação e preservação da Sanga da Divisa e programas de Educação Ambiental junto a Secretaria Municipal de Meio Ambiente, constatou-se a inexistência de projetos. Porém, no ano de 2000, durante a Semana da água, ocorreu um mutirão de limpeza da Sanga denominado "SOS - Divisa Limpa", coordenado pelo Departamento de Meio Ambiente, EMATER e CORSAN, ambas do município.

O evento contou com a participação de 1200 pessoas, onde foram recolhidos cerca de 30 toneladas de resíduos de diversos tipos, como sofás, sacolas plásticas, restos de matérias de construção, latas e garrafas pet (Figura 1) das margens da Sanga. Isso revelando uma falta de conscientização ambiental dos moradores, visto que o local estava sendo utilizado como depósito desses resíduos, oriundos das residências localizadas no entorno da área, lembrando que esses dejetos são de demora decomposição, podendo afetar significativamente o ambiente, além de promoverem a poluição do solo e da água.

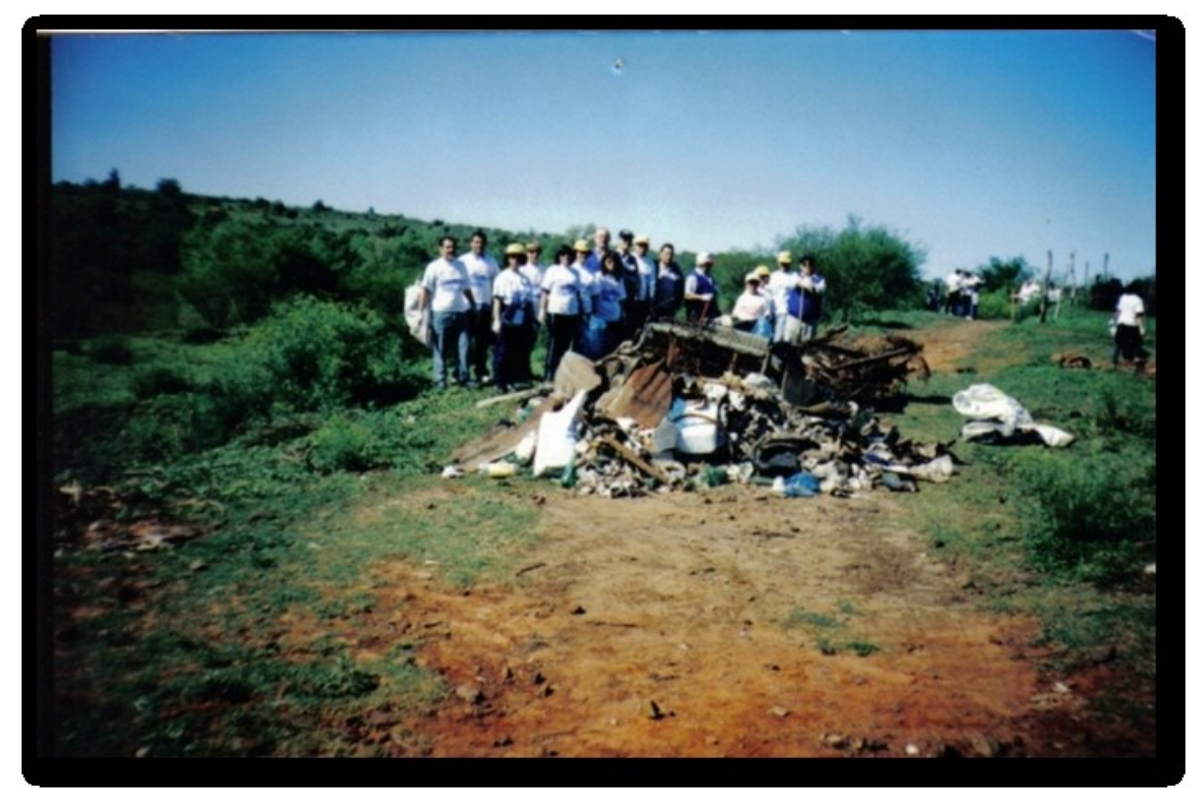

Figura 1 - Resíduos sólidos recolhidos durante o mutirão de limpeza da Sanga da Divisa. Quaraí, RS Fonte: Secretaria Municipal de Meio Ambiente, Quaraí, RS.

Após o mutirão, ainda foram implantadas 14 placas educativas como forma de conscientizar a população quanto à preservação da Sanga, além disso, foram colocadas 7 lixeiras nos bairros ao longo da Sanga para que não houvesse mais a deposição inadequado de resíduos naquela área.

Dessa forma a Educação Ambiental é fundamental para o sucesso de projetos ou programas realizados para sensibilização da comunidade com relação aos resíduos sólidos, pois, através de programas educativos relacionados a esta questão e que garantem seu uso racional, evita-se o agravamento de problemas ambientais gerados por esses.

Através de informações obtidas na EMATER, no que diz respeito a programas e campanhas educativas acerca de temas relacionados ao ambiente, palestras são realizadas em estabelecimentos de ensino do município, a fim de conscientizar a população sobre as questões que afetam o ambiente, estas realizadas em conjunto com a CORSAN e prefeitura municipal.

No ano de 2001 após o mutirão, ocorreu um trabalho de sensibilização junto aos moradores próximos à Sanga da Divisa com o objetivo de sensibilizar sobre os cuidados e destino 
correto dos resíduos e, no ano seguinte aconteceu um Pedágio Educativo a fim de promover uma ampla conscientização sobre a problemática causada pelos resíduos sólidos.

Sabemos que a Educação Ambiental busca abrir os nossos olhos, mostrando que o ser humano é apenas mais uma parte do ambiente em que vive além de tratar de assuntos relacionados à proteção e uso racional dos recursos naturais também deve estar focada na proposição de ideias e princípios que possibilitem a construção de um mundo sustentável.

A Educação Ambiental, de acordo com a Lei 6.938, de 31 de agosto de 1981, em seu Art. $2^{\circ}$, no inciso $\mathrm{X}$ cita um dos princípios a serem atendidos é a "educação ambiental a todos os níveis de ensino, inclusive a educação da comunidade, objetivando capacitá-la para participação ativa na defesa do meio ambiente".

A Lei 9.795, que dispõe sobre a educação ambiental, institui a Política Nacional de Educação Ambiental, considera que a educação ambiental é "um componente essencial e permanente da educação nacional, devendo estar presente, de forma articulada, em todos os níveis e modalidades do processo educativo, em caráter formal e não-formal". (BRASIL, 1999).

Segundo a Constituição da República Federativa do Brasil de 1988 no Art. 225, inciso $1^{\circ}$ do VI parágrafo, diz o seguinte:

Promover a Educação Ambiental em todos os níveis de ensino e conscientização publica para a preservação do meio ambiente. Todos têm direito ao meio ambiente ecologicamente correto, bem de uso comum do povo e essencial a sadia qualidade de vida, impondo-se ao poder público e a coletividade o dever de defender e preservá-lo para as presentes e futuras gerações. (Brasil, 1988).

A Educação Ambiental, como componente essencial no processo de formação e educação permanente, com uma abordagem direcionada para a resolução de problemas, contribui para o envolvimento ativo do público, torna o sistema educativo mais relevante e mais realista e estabelece uma maior interdependência entre estes sistemas e o ambiente natural e social, com o objetivo de um crescente bem estar das comunidades humanas.

\section{Visitas em campo: registros fotográficos}

Os registros fotográficos na Sanga da Divisa ocorreram durante o mês de setembro de 2014, deram início a partir ponte da BR 377, onde já foi possível evidenciar a deposição inadequada de resíduos sólidos às margens do córrego, lembrando que a escolha desse trecho que termina nas imediações da ponte da Avenida 20 de Setembro, justificou-se em virtude de ser o trecho da Sanga com maior proximidade com a zona urbana do município.

Através destes registros fotográficos pode-se obter um quadro da atual situação ambiental em que a Sanga da Divisa se encontra, permitindo a identificação de problemas como a deposição inadequada de resíduos sólidos às suas margens, além disso, outros impactos como o despejo de esgoto cloacal e a ausência da mata ciliar em alguns trechos foram observados, evidenciando-se assim um potencial de degradação ambiental ao córrego.

Esses resultados mencionados acima se tornam cada vez mais preocupantes, uma vez que a existência de resíduos sólidos às margens da Sanga (Figura 2) e esgoto a céu aberto podem indicar a falta de uma coleta de resíduos adequada e de um saneamento básico que atenda as necessidades daquela área, tendo em vista que estes elementos estão diretamente ligados às questões de saúde humana e de qualidade de vida da população. 


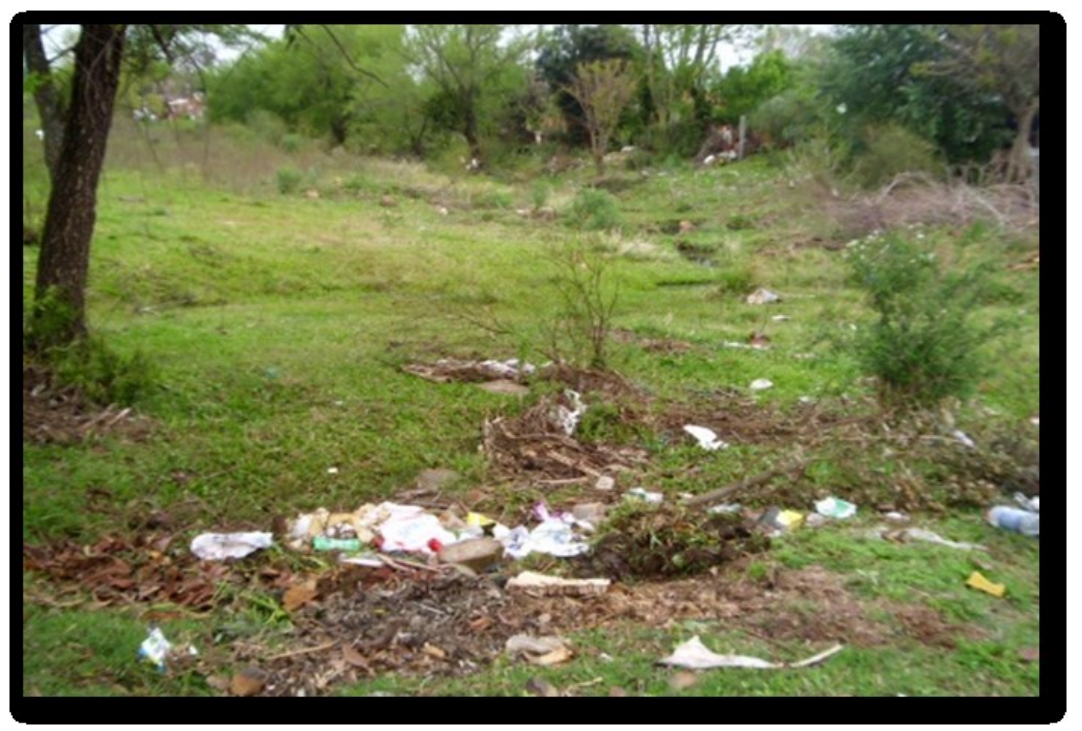

Figura 2 - Resíduos Sólidos depositados na margem direita da Sanga da Divisa. Quaraí, RS. Fonte: MOREIRA, Galidulcidio - 2014.

A agressão ambiental à Sanga, por meio da deposição de resíduos sólidos, eleva o nível de degradação do ambiente devido à diversidade e quantidade de resíduos que ali observados, revelando a falta conscientização ambiental das pessoas, que não tem nenhuma preocupação com o descarte desses resíduos, poluindo e contaminando o solo, a água.

Com a Constituição Federal de 1988, os resíduos sólidos foram tratados com maior importância devido ao seu alto grau poluidor. Os incisos VI e IX do Art. 23 estabelecem ser competência da União, dos estados, do Distrito Federal e dos municípios proteger o meio ambiente e combater a poluição em qualquer de suas formas. (BRASIL, 1988).

Segundo a Lei 12.305 de 02 de agosto de 2010, que institui a Política Nacional dos Resíduos Sólidos, e estimula a criação dos planos municipais de gestão integrada dos resíduos sólidos, no Art. 47, diz que são proibidas as seguintes formas de destinação ou deposição de resíduos ou rejeitos:

[...] I - lançamento em praias, no mar ou em quaisquer corpos hídricos; II - lançamento in natura a céu aberto, excetuados os resíduos de mineração; III - queima a céu aberto ou em recipientes, instalações e equipamentos não licenciados para essa finalidade. (BRASIL, 2010). Dessa forma a conscientização coletiva e individual, através de projetos ou programas de Educação Ambiental direcionado a população em geral, com a finalidade de conscientizá-la a respeito da degradação dos recursos hídricos através da deposição inadequada de resíduos sólidos e, proporcionar a todas as pessoas, a possibilidade de adquirir os conhecimentos, o sentido dos valores, as atitudes, o interesse ativo a as atitudes para proteger e melhorar o ambiente faz-se necessária.

Observou-se que a maior quantidade de resíduos depositados encontra-se na margem direita, essa grande presença muitas vezes se deve ao fato de que algumas residências chegam a distar 30 metros da margem da Sanga, enquanto que, a margem esquerda, por não possui muita influência urbana não há praticamente a presença desses resíduos. 
No que consta na Lei $\mathrm{n}^{\circ} 12.651$, de 25 de maio de 2012, em seu Art. $4^{\circ}$, inciso I:

[...] as faixas marginais de qualquer curso d'água natural perene e intermitente, excluídos os efêmeros, desde a borda da calha do leito regular, devem distar em largura mínima de 30 metros, para os cursos d'água de menos de 10 metros de largura e 50 metros, para os cursos d'água que tenham de 10 a 50 metros de largura. (Brasil, 2012).

Conforme um levantamento fotográfico realizado da Sanga em 1999 pela prefeitura municipal, ficou evidente de que a degradação a este curso d' água já vem ocorrendo há anos, revelando-se assim a falta de conscientização da população e do Poder Público, como se pode observar na (figura 3) que retrata a situação das margens da Sanga naquela época.

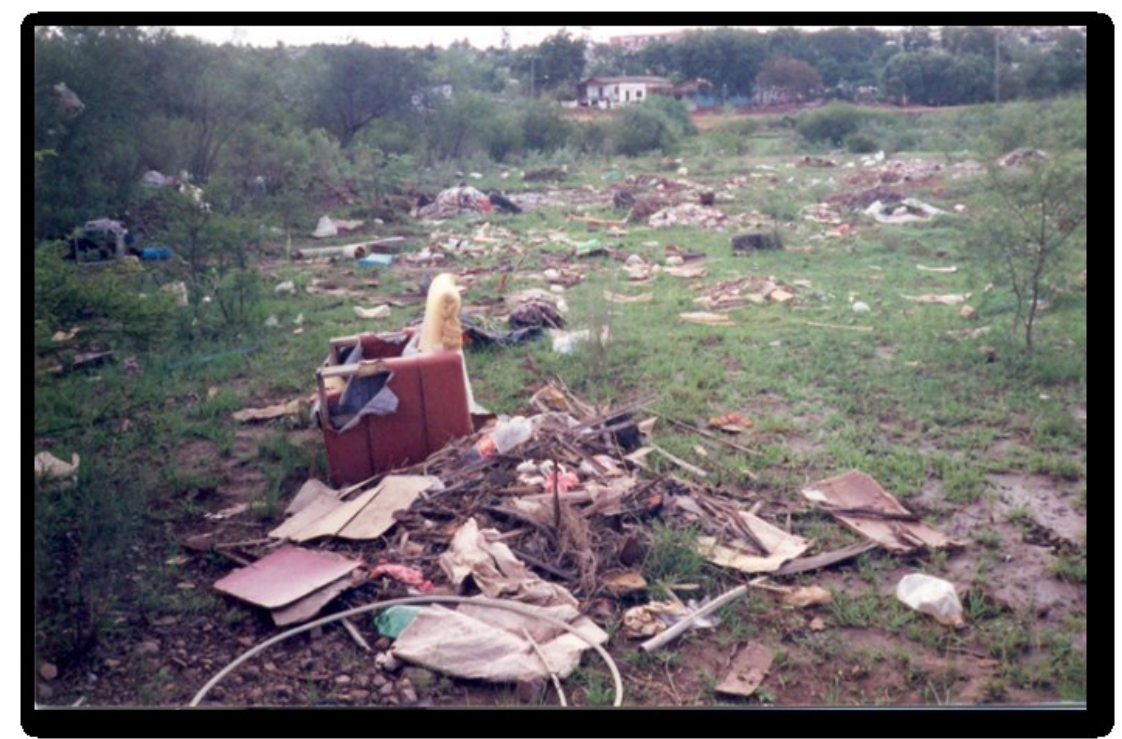

Figura 3 - Resíduos Sólidos as margens da Sanga da Divisa. Quaraí, RS.

Fonte: Secretaria Municipal de Meio Ambiente, Quaraí-RS.

Verifica-se, através desta imagem, que as ações antrópicas vêm promovendo efeitos negativos sobre o ambiente desde essa época, principalmente sobre os recursos hídricos existentes e que, as diversas práticas adotadas pelos moradores como a deposição inadequada de resíduos sólidos as margens do córrego, de forma direta ou indireta, possuem papel fundamental na geração dos impactos observados, principalmente no que diz respeito à degradação do solo e da água.

Diante dessa questão, a elaboração de um programa de reeducação da população com relação à geração e à deposição de resíduos sólidos poderá contribuir para minimizar impactos socioambientais significativos que acarretam a Sanga.

No atual contexto de degradação ambiental a Educação Ambiental tem o papel de promover uma distribuição igualitária de conhecimento na medida em que proporciona a formação de capacidades para que as pessoas e comunidades participem da tomada de decisões em relações as questões ambientais em todas as suas dimensões.

Um agravante para este tipo de situação é de que além dos resíduos depositados inadequadamente às margens da Sanga da Divisa, ela vem sofrendo constantemente com cargas de esgoto cloacal despejados diretamente em seu leito (Figura 4) sem nenhum tipo de tratamento, ações como essa vêm gerando impactos sobre o ambiente, causando a poluição do mesmo e comprometendo ainda mais a qualidade ambiental do córrego. 


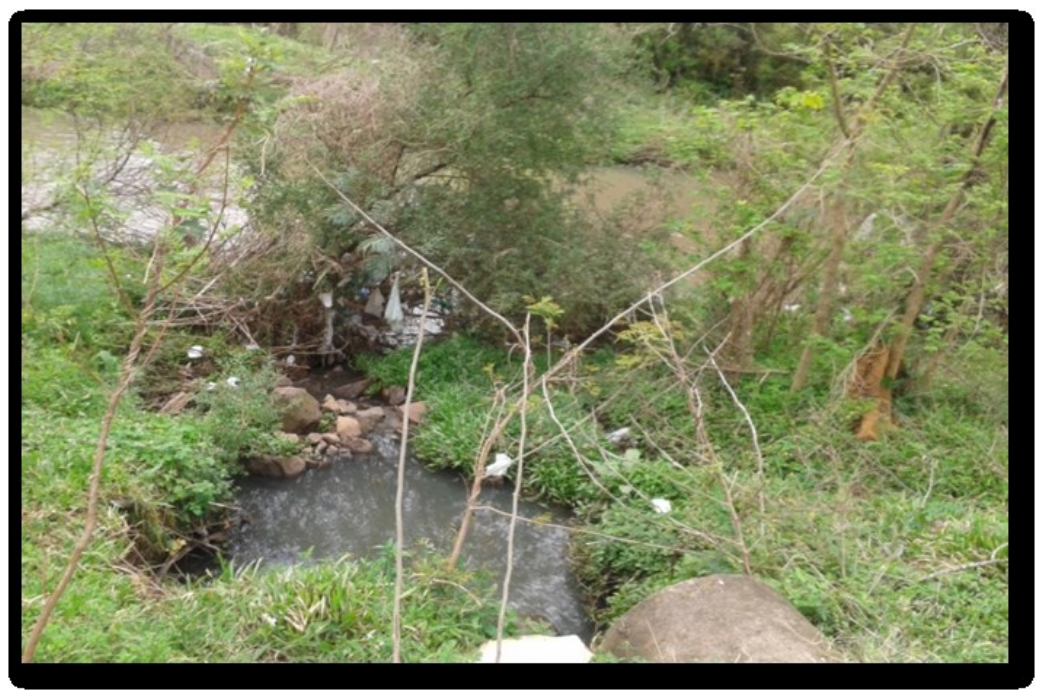

Figura 4 - Lançamento de esgoto cloacal na Sanga da Divisa. Quaraí, RS. Fonte: MOREIRA, Galidulcidio - 2014.

O lançamento de esgoto cloacal contribui para aumentar o grau de deterioração da água da Sanga. Durante os registros fotográficos foram identificados em diversos pontos do córrego, esse tipo de degradação (Figura 5).

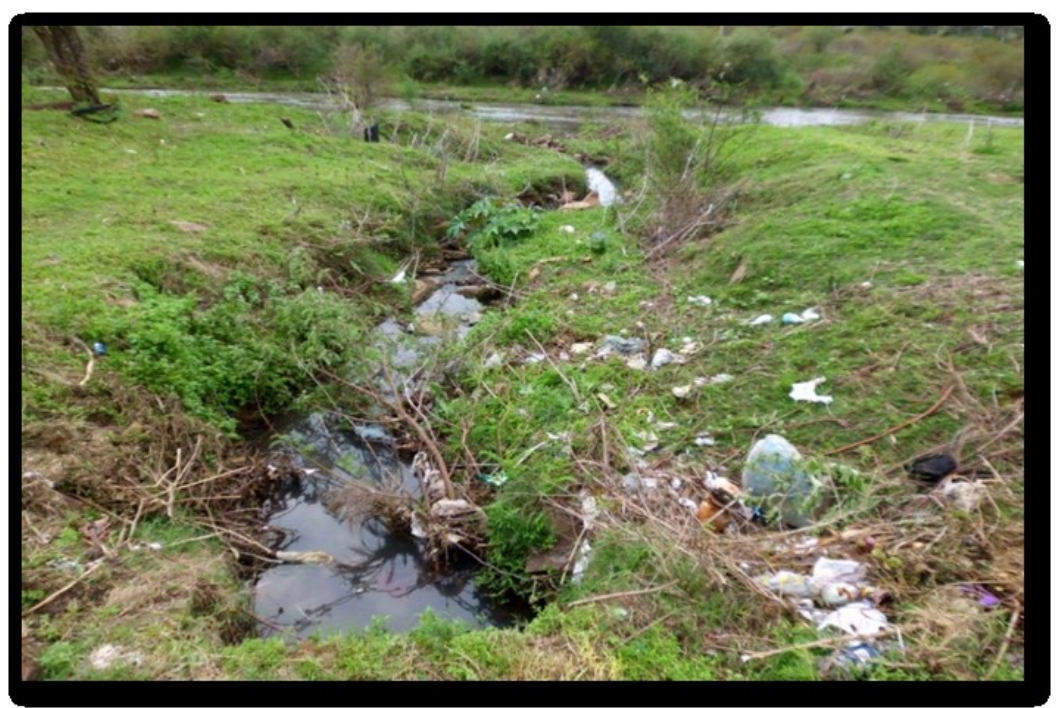

Figura 5 - Esgoto cloacal sendo despejado diretamente na Sanga da Divisa. Quaraí, RS Fonte: MOREIRA, Galidulcidio - 2014.

A falta de Saneamento Básico compromete diretamente a qualidade da água da Sanga e a saúde da população ribeirinha, causando uma preocupação, uma vez que a existência de esgoto a céu aberto indica a falta ou a defasagem de saneamento básico, fato que está diretamente ligado a questões de saúde humana, de qualidade de vida e de conservação dos recursos naturais, especialmente da água.

A Lei 11.445 de 05 de janeiro de 2007, denominada Lei do Saneamento Básico, estabelece diretrizes nacionais para o Saneamento Básico e institui a Política Federal de Saneamento Básico, que tem como primeiro objetivo a universalização do acesso ao saneamento básico, abrangendo a zona urbana e a zona rural dos municípios.

O saneamento básico é um dos principais indicadores da qualidade de vida e do desenvolvimento econômico e social de uma cidade. Para isso deverá ser realizado pelo Poder Público da cidade, mas em contrapartida a população também deverá colaborar, visto que de 
nada vai adiantar ter um bom saneamento se ela não tiver a consciência de que jogando resíduos dentro da Sanga, poderá causar a contaminação da água e do solo.

Pode-se dizer que as condições ambientais da Sanga da Divisa não são reflexos apenas das ações da sociedade ao longo dos anos, mas também o Poder Público tem sua parcela, pois segundo informações obtidas na CORSAN, atualmente no município de Quaraí, cerca de 14\% do esgoto é cobrado, e em torno de 30 à $40 \%$ é tratado.

Por fim, outro fator observado em relação à Sanga da Divisa e que contribui para aumentar a sua degradação é a ausência da mata ciliar em diversos trechos, havendo uma comparação entre as margens, a que apresenta maior ausência de mata ciliar é a margem direita (Figura 6), pois é a que sofre intensa influência antrópica.

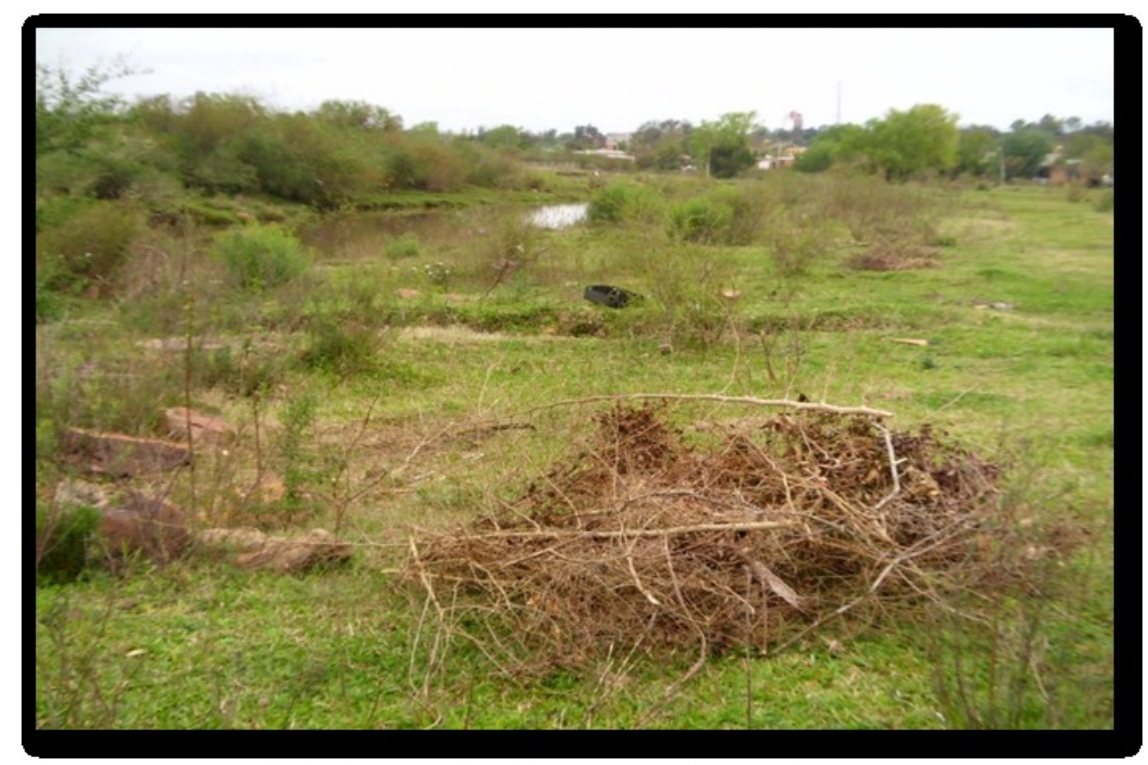

Figura 6 - Margem direita da Sanga da Divisa, bastante desmatada. Quaraí, RS. Fonte: MOREIRA, Galidulcidio - 2014.

A Sanga necessita de vegetação ao seu redor, pois ela é quem impede a entrada de sedimentos como restos de matérias de construção e resíduos sólidos que são descartados pela população, impedindo que a mesma acabe assoreando e continue servindo ainda de fonte de recursos para uma grande quantidade de seres vivos. Além disso, a ausência dessa cobertura vegetal contribui aumenta o escoamento superficial e consequentemente remove a superfície do solo através do processo erosivo.

Diante desse processo de degradação ambiental que acomete ao córrego Sanga da Divisa detectado nesse estudo, faz-se necessário a participação da população no sentido de valorização desse ecossistema muito importante para o município, e na busca de alternativas para minimizar os impactos ambientais que a atingem.

Uma das alternativas é o desenvolvimento de programas de Educação Ambiental voltados para a problemática da Sanga, que deve ser um instrumento que possibilite informar, sensibilizar e mobilizar toda a sociedade na participação efetiva no processo de modificação do quadro de degradação ambiental. 
De acordo com o Art. 13 da Lei 9.795, parágrafo único, o Poder Público, em níveis federal, estadual e municipal, incentivará:

[...] I - a difusão, por intermédio dos meios de comunicação de massa, em espaços nobres, de programas e campanhas educativas, e de informações acerca de temas relacionados ao meio ambiente; II - a ampla participação da escola, da universidade e de organizações nãogovernamentais na formulação e execução de programas e atividades vinculadas à educação ambiental não-formal; III - a participação de empresas públicas e privadas no desenvolvimento de programas de educação ambiental em parceria com a escola, a universidade e as organizações não-governamentais; IV - a sensibilização da sociedade para a importância das unidades de conservação; V - a sensibilização ambiental das populações tradicionais ligadas às unidades de conservação; VI - a sensibilização ambiental dos agricultores; VII - o ecoturismo. (BRASIL, 1999).

O conhecimento sobre impactos ambientais na Sanga da Divisa inspira conscientização da população local, a água por ser um recurso indispensável à vida da humanidade, propicia a prática da Educação Ambiental, diante disso se torna importante à aplicação de instrumentos como a Educação Ambiental duradoura junto à população com o objetivo de mudanças de hábitos e comportamentos buscando assim alcançar a sustentabilidade.

Para isso é preciso se ter uma Educação Ambiental eficiente que prime pela construção do conhecimento critico, diferente da educação ambiental que dá prioridade a divulgação de informações sem preocupação com a conscientização do cidadão, e não deixar que essa educação seja apenas considerada como um simples repasse de informações relacionadas ás questões ambientais.

\section{Medidas para recuperação e preservação da área}

A partir do estudo realizado na Sanga da Divisa, ficou evidente a necessidade do desenvolvimento de programas de Educação Ambiental voltados para os problemas ambientais enfrentados pelo município com o objetivo de modificar hábitos e comportamento da população, conscientizá-la a respeito dos problemas que as cerca.

Sendo assim, propõem-se medidas mitigadoras para possível recuperação e preservação da Sanga da Divisa, Quaraí-RS com o objetivo de minimizar os impactos negativos causados a qualidade das águas e do solo do córrego, fornecendo instrumentos para uma atuação mais ativa no sentido de modificar essa realidade, tendo em vista que há algum tempo atrás este curso d'água servia como local de trabalho para lavadeiras (Figura 7) e uma área de lazer.

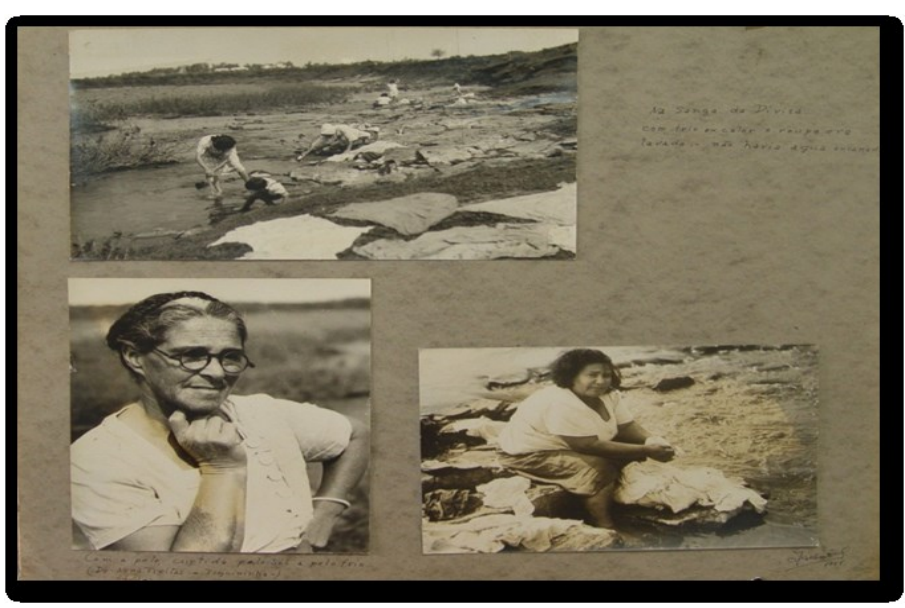

Figura 7 - Lavadeiras na Sanga em 1951. Quaraí, RS.

Fonte: Secretaria Municipal de Meio Ambiente, Quaraí-RS. 
A implantação de um projeto ou programa permanente de Educação Ambiental com o envolvimento da população local ocorre de modo a prevenir as contaminações provocadas pela deposição de resíduos sólidos no entorno da Sanga e não apenas em determinados períodos ações preventivas no local.

Também é preciso que haja uma atuação maior do Poder Público em relação à elaboração de programas de Educação Ambiental como, por exemplo, de coleta seletiva no município, principalmente nos bairros ao longo da Sanga da Divisa, com a destinação adequada dos resíduos sólidos coletados, esse projeto será de grande valia para o município, pois, poderia reduzir significativamente os riscos de degradação ambiental, não somente na área da Sanga, mas sim na cidade como um todo.

Outra medida seria a elaboração de uma cartilha, a fim de revelar a atual situação em que a Sanga da Divisa se encontra esta cartilha ainda servindo como material para o desenvolvimento de projetos de Educação Ambiental no município, onde escolas estaduais e municipais poderão desenvolver trabalhos que abordem essa temática.

Os projetos devem ser desenvolvidos de modo a envolver professores, alunos e a comunidade, pois quando são criados laços afetivos entre escola e comunidade, os problemas ambientais que antes não eram responsabilidade de ninguém, passam a ser de todos.

Medidas mitigadoras a serem adotadas para o controle dos danos ambientais decorrentes da deposição de resíduos sólidos na Sanga da Divisa, Quaraí-RS:

- Divulgação do diagnóstico ambiental da Sanga da Divisa para a gestão ambiental do município, a fim de revelar a atual situação em que se encontra o córrego;

- Realizar o recolhimento dos resíduos sólidos existentes às margens da Sanga da Divisa em conjunto com a EMATER, CORSAN, e prefeitura municipal;

- Desenvolver projetos permanentes de Educação Ambiental nas escolas, e repartições públicas, envolvendo a Sanga da Divisa;

- Estimular o desenvolvimento de programas de capacitação em Educação Ambiental voltados para professores municipais e estaduais;

- Incentivar a participação da sociedade na cobrança de atitudes da administração pública com relação à degradação ambiental que ocorre a Sanga da Divisa;

- Promover ações de Educação Ambiental, através de visitas, palestras campanhas de conscientização fazendo referência aos problemas ambientais locais do município em instituições de ensino e residências próximas a Sanga;

- Implantação de rede coletora de esgoto no âmbito de toda a Sanga da Divisa.

\section{Conclusões}

O presente estudo mostrou que as condições ambientais do córrego Sanga da Divisa, Quaraí-RS são reflexos das ações da sociedade ao longo dos anos e o descaso do Poder Público que contribui para a intensificação dos processos de degradação deste curso d' água.

Diante vários aspectos apresentados neste trabalho, foi constatado que o trecho localizado entre a ponte da BR 377 e a ponte da Avenida 20 de Setembro se encontra num progressivo processo de degradação ambiental, por diversos fatores sendo o principal deles a deposição inadequada de resíduos sólidos, ocasionando sérios danos ambientais a Sanga.

Nota-se um descaso do Poder Público, em relação a programas permanentes de Educação Ambiental voltados a comunidade, além disso, foi observado que atualmente não existe nenhum projeto que vise a recuperação e preservação da Sanga da Divisa.

Pode-se dizer que a minimização dos impactos que acometem o córrego, requer uma reeducação ambiental da comunidade ribeirinha e da população do município para que a mesma construa uma consciência com relação à problemática ambiental, respeitando assim as limitações do ecossistema, tendo conhecimento que qualquer interferência pode resultar em desiquilíbrio no ambiente.

Os registros fotográficos revelam às atividades antrópicas aliadas à falta de conscientização por parte da polução, como a deposição de resíduos sólidos ao longo da Sanga, causando uma instabilidade ambiental e uma consequente perda da qualidade ambiental. Cabe 
ainda destacar que este curso d' água que hoje passa por esse processo de degradação é um recurso muito importante para o município por se tratar do principal afluente do rio Quaraí.

Portanto são imprescindíveis que sejam tomadas algumas medidas de recuperação e preservação da área para amenizar os danos ambientais como os que foram citados neste trabalho, pois, o desenvolvimento de projetos e programas de Educação Ambiental com o enfoque na Sanga, além de conscientizar a população a respeito dos problemas ambientais que a envolve, fornecerá instrumentos para busca da melhoria da qualidade de vida.

\section{Referências}

BRASIL. Constituição (1988). Constituição da República Federativa do Brasil: promulgada em 5 de outubro de 1988: atualizada até a Emenda Constitucional n. 84, de 2-12-2014. Disponível em: <http://www.planalto.gov.br/ccivil_03/constituicao/constituicaocompilado.htm>. Acesso em: 15 dez. 2014.

BRASIL. Lei n. 6.938, de 31 de agosto de 1981. Dispõe sobre a Política Nacional do Meio Ambiente, seus fins e mecanismos de formulação e aplicação, e dá outras providências. Diário Oficial da União. Brasília, DF, 02 set. 1981. Disponível em:

<http://www.planalto.gov.br/ccivil_03/leis/16938.htm>. Acesso em: 9 out. 2014.

BRASIL. Lei n ${ }^{\circ} 9.795$ de 27 de abril de 1999. Dispõe sobre a educação ambiental, institui a Política Nacional de Educação Ambiental e dá outras providências. Diário Oficial da União. Brasília, DF, 27 abr. 1999. Disponível em:

<http://www.planalto.gov.br/ccivil_03/leis/19795.htm>. Acesso em: 16 dez. 2014.

BRASIL. Lei n. 11.445, de 5 de janeiro de 2007. Estabelece diretrizes nacionais para o saneamento básico; altera as Leis nos 6.766, de 19 de dezembro de 1979, 8.036, de 11 de maio de 1990, 8.666, de 21 de junho de 1993, 8.987, de 13 de fevereiro de 1995; revoga a Lei no 6.528, de 11 de maio de 1978; e dá outras providências. Diário Oficial da União. Brasília, DF, 08 jan. 2007. Disponível: <http://www.planalto.gov.br/ccivil_03/_ato2007-

2010/2007/lei/111445.htm>. Acesso em: $28 \mathrm{dez} .2014$.

BRASIL. Lei n. 12.305, de 02 de agosto de 2010. Institui a Política Nacional de Resíduos Sólidos; altera a Lei no 9.605, de 12 de fevereiro de 1998; e dá outras providências. Diário Oficial da União. Brasília, DF, 03 ago. 2010. Disponível em: <http://www.planalto.gov.br/ccivil_03/_ato2007-2010/2010/lei/112305.htm>. Acesso em: 10 out. 2014.

BRASIL. Lei n. 12.651, de 25 de maio de 2012. Dispõe sobre a proteção da vegetação nativa; altera as Leis nos 6.938, de 31 de agosto de 1981, 9.393, de 19 de dezembro de 1996, e 11.428, de 22 de dezembro de 2006; revoga as Leis nos 4.771, de 15 de setembro de 1965, e 7.754, de 14 de abril de 1989, e a Medida Provisória no 2.166-67, de 24 de agosto de 2001; e dá outras providências. Diário Oficial da União. Brasília, DF, 28 mai. 2012. Disponível em: <http://www.planalto.gov.br/ccivil_03/_ato2011-2014/2012/lei/112651.htm>. Acesso em: 29 dez. 2014.

DEGRADAÇÃO AMBIENTAL. In: Wikipédia, a enciclopédia livre. Disponível em: $<$ http://pt.wikipedia.org/wiki/Degrada\%C3\%A7\%C3\%A3o_ambiental>. Acesso em: 23 out. 2014 .

GRACIOLI, C. R.; Impactos ambientais na microbacia do Rio Vacacaí - Mirim em Santa Maria - RS. 2005. 236f. Dissertação (Mestrado em Engenharia Florestal) Universidade de Santa Maria, Santa Maria, 2005. 
IBGE. INSTITUTO BRASILEIRO DE GEOGRAFIA E ESTATÍSTICA. Quaraí: dados gerais do município. Disponível em<http://cidades.ibge.gov.br/painel/painel.php?codmun=431530>. Acesso em: 10 set. 2014.

QUARAÍ (RS). Prefeitura. Projeto Executivo: Desassoreamento da Sanga da Divisa, Quaraí, RS. 2005. 47f. Quaraí, RS. 